\title{
Analysis of the Application of a Nanosecond Laser Pulse for Dynamic Hardness Tests Under Ultra-High Strain Rates
}

\author{
W. Moćko ${ }^{1}$ (D) J. Radziejewska ${ }^{2}$
}

Received: 9 April 2018 / Accepted: 3 January 2019 /Published online: 28 January 2019

(C) The Author(s) 2019

\begin{abstract}
Experimental and numerical tests of surface plastic deformation generated under different strain rates were performed. Deformations were introduced by both classical Brinell and laser pulse hardness tests. An Nd:YAG laser with a wavelength of $1064 \mathrm{~nm}$ and a laser pulse time length of $10 \mathrm{~ns}$ was used to generated a shock wave to induce local plastic deformation on the material surface. The laser pulse induces a repeatable plastic deformation of a surface without thermal effects on the surfaces. Based on imprint geometry, the dynamic hardness of materials was evaluated at a strain rate of the order $107 \mathrm{~s}-1$. Numerical analyses carried out included quasi-static and dynamic Brinell hardness tests and laser pulse interactions with materials. The Rusinek-Klepaczko constitutive model applied in the calculations allows the prediction of the mechanical characteristics at a strain range strain range from 10 to $4 \mathrm{~s}-1$ to $107 \mathrm{~s}-1$. Numerical and experimental results from the surface plastic deformations show close agreement.
\end{abstract}

Keywords Laser pulse $\cdot$ Dynamic hardness $\cdot$ Plastic deformations $\cdot$ Metals

\section{Introduction}

Experimental and numerical tests of surface plastic deformation were generated under different strain rates. Deformations were introduced by classical Brinell's or laser pulse hardness tests [1]. The Nd:YAG laser with a wavelength of $1064 \mathrm{~nm}$ and a laser pulse time length of $10 \mathrm{~ns}$ was used to generated a shock wave in order to induce local plastic deformation of surface layer. The laser pulse induces a repeatable plastic deformation without thermal effects on the surfaces. Based on imprint geometry; the dynamic hardness has been evaluated at a strain rate of the order $10^{7} \mathrm{~s}^{-1}$. The numerical analyses have included quasi-static and dynamic Brinell hardness tests as well as laser pulse interactions with materials. The Rusinek-Klepaczko constitutive model (R-K) [2],

W. Moćko

wojciech.mocko@its.waw.pl

1 Motor Transport Institute, 80 Jagiellońska St., 03-301 Warsaw, Poland

2 Faculty of Production Engineering, Warsaw University of Technology, 85 Narbutta St., 02-524 Warsaw, Poland applied in the calculations, has enabled to predict mechanical characteristics at a strain range from $10^{-4} \mathrm{~s}^{-1}$ to $10^{7} \mathrm{~s}^{-1}$. The umerical and experimental results of surface plastic deformations have shown good agreement.

\section{Experimental Methodology}

Three different materials were selected for the analysis: commercial pure aluminium, copper and stainless steel (AISI304). Mechanical properties under quasi-static loading conditions were determined at room temperature within a range of strain rates from $10^{-4} \mathrm{~s}^{-1}$ to $10^{-2} \mathrm{~s}^{-1}$ using a servo-hydraulic testing machine [3]. At high strain rate loading conditions, the split Hopkinson bar methodology [4] and the miniaturized direct impact compression test method were applied [3] to obtain strain rates ranging from $4 \times 10^{4} \mathrm{~s}^{-1}$ to $8 \times 10^{4} \mathrm{~s}^{-1}$. The Brinell hardness was determined using a $2.5 \mathrm{~mm}$ radius steel ball and $613 \mathrm{~N}$ load according to EN-ISO 6506-1:2005.

The hardness was defined as a specific work of plastic deformation. This approach was applied for both the typical hardness measurements using an indenter and the determination of the dynamic hardness by laser pulse. The force was estimated on the basis of the pressure generated as a result of the laser pulse interaction with material [5]. 


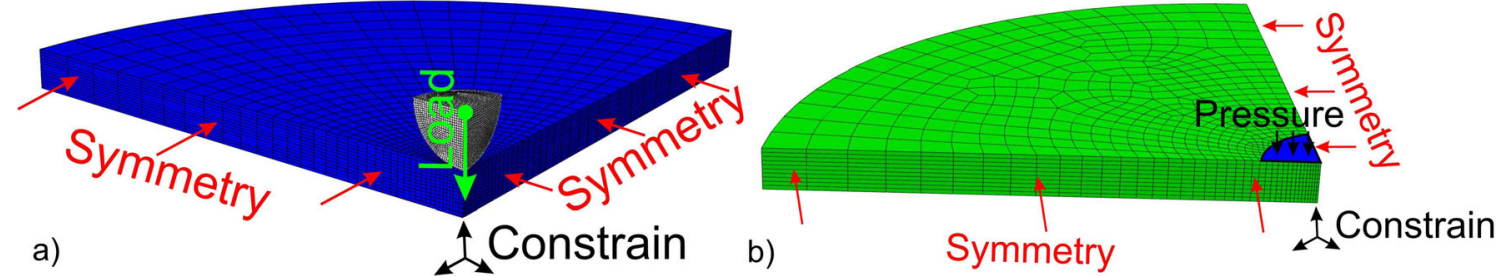

Fig. 1 Numerical model of indentation test using $2.5 \mathrm{~mm}$ steel ball (a) and nanosecond laser pulse (b)

\section{Numerical Analysis Results}

Arrangement of the indentation test using a $2.5 \mathrm{~mm}$ steel ball $(\mathrm{SBH})$ was simulated by a specimen with a fully confined bottom surface and the rigid indenter tip (Fig. 1(a)). The viscoplastic behaviour of the analysed materials are represented by the R-K model calibrated on the basis of a series of compressive tests and reference data. The model of the specimen and indenter was quarter symmetric to decrease simulation time. C3D8R elements were used to mesh both specimen and indenter tip. The density of the mesh in the plastic deformation region was increased to obtain element dimensions equal to $0.05 \mathrm{~mm} \times 0.05 \mathrm{~mm} \times 0.05 \mathrm{~mm}$. The course of the applied load was of a triangular shape of magnitude equal to the maximal indentation force applied in the experiment. Numerical calculations were performed using ABAQUS Explicit solver.

The influence of plasma on the surface of the specimen may be modelled as a pressure pulse with a given time and spatial distribution. The spatial distribution of the pressure on the specimen surface was described by the equation proposed in $[6]$ :

$P(x, y, t)=P(t) \exp \left[-0.85\left(x^{2}+y^{2}\right) / R^{2}\right]$

where: $R$ - radius of the laser beam.

To simulate the history of the plasma pulse pressure evolution with time, $P(t)$ data, introduced by Peyre, [7] were applied. The bottom specimen surface was constrained, whereas pressure generated due to laser action was applied to the central region of the opposite surface (Fig. 1(b)).

Figure 2 shows the experimentally obtained profiles of imprints induced by a nanosecond laser pulse at various energies. Analysing numerical results, calculated at various laser pulse energies (Fig. 3), it may be found that with an increase in the energy both the depth and diameter of imprints are enlarged. The shape of the imprints is dependent on the mechanical properties of a given material. Steel is characterized by the highest yield stress (500 MPa) among analysed materials and good work hardening effect independent of strain rate. As a
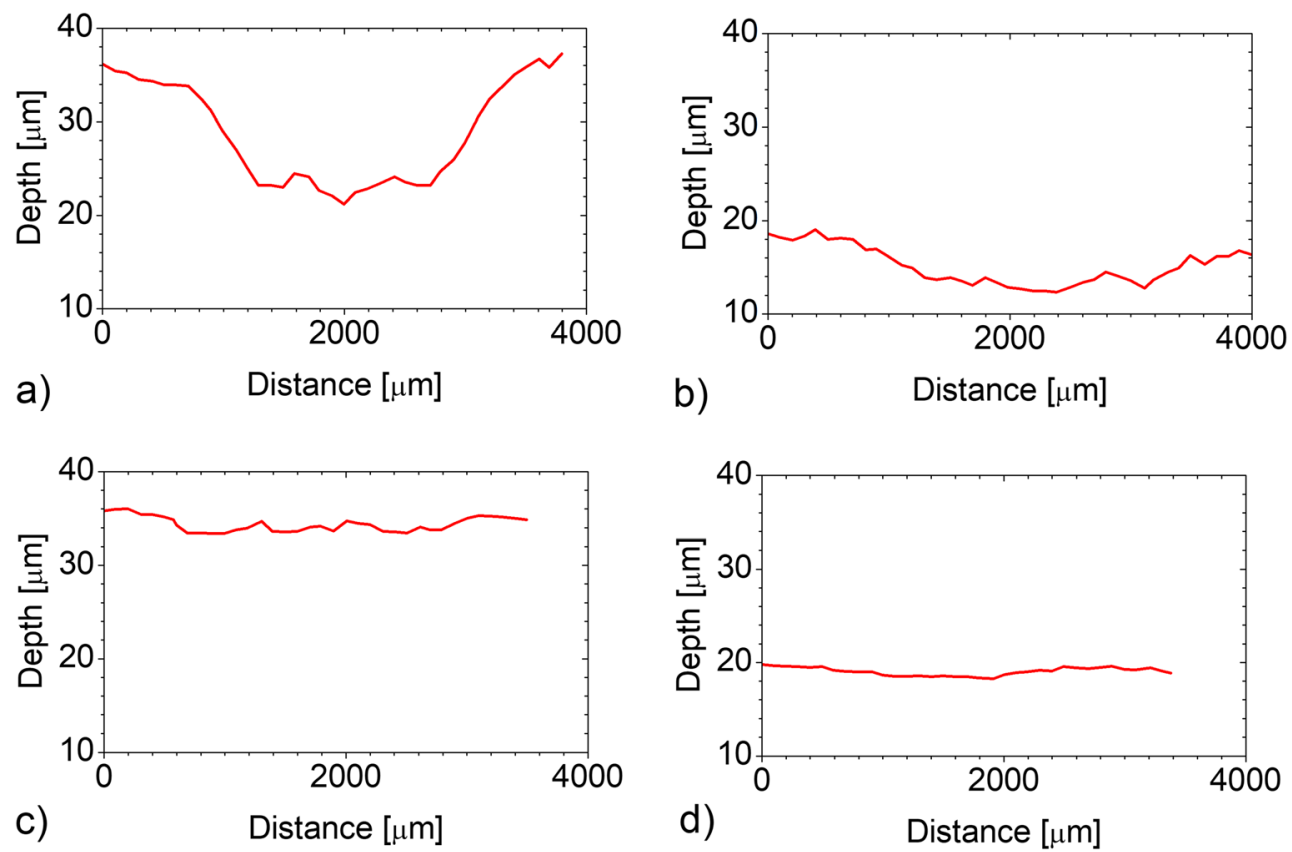

Fig. 2 Imprints on surface of: (a) - Al $0.7 \mathrm{~J}$, (b) - Cu $1.1 \mathrm{~J},(\mathbf{c})$ - Cu $0.7 \mathrm{~J},(\mathbf{d})$ - steel 304, generated by the shock wave induced by $10 \mathrm{~ns}$ laser pulse 

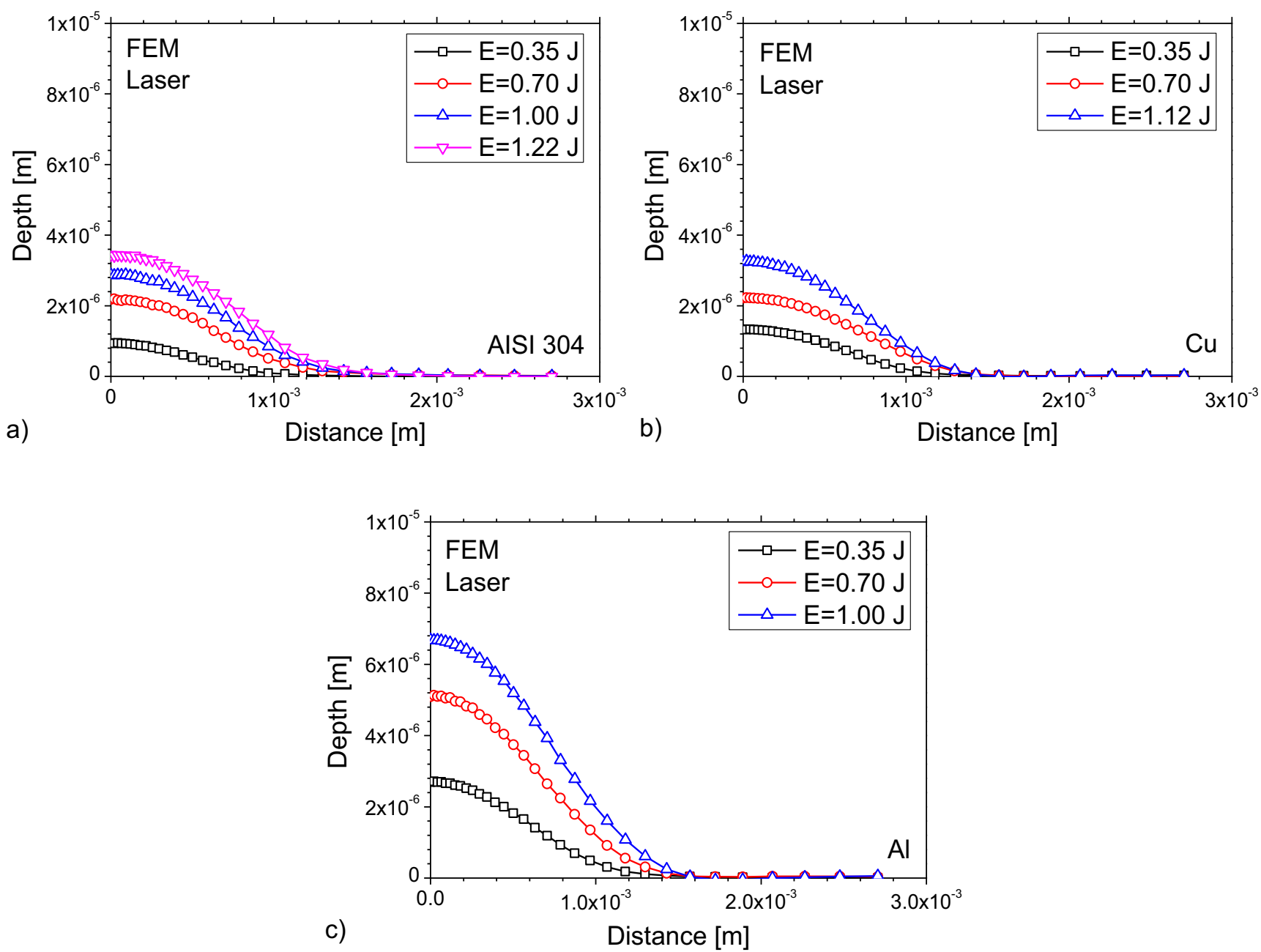

Fig. 3 Numerically calculated profiles of imprints induced by a laser pulse at various energies for: (a) AISI 304 steel; (b) $\mathrm{Cu}$; (c) Al

consequence, the depth of the imprint induced by a laser pulse is limited. In the case of $\mathrm{Cu}$, the yield stress is lower than for steel (300 MPa), but the modulus of plastic hardening significantly increases with strain rate. Therefore, at the very high strain rates observed during indentation induced by a laser pulse, the work hardening effect is very strong, comparable to those estimated for steel. Finally, the indentation depth for $\mathrm{Cu}$ has similar values to those determined in the case of steel. The yield stress of $\mathrm{Al}$ is close to that for $\mathrm{Cu}(300 \mathrm{MPa})$; however, this material shows a very limited work hardening effect which is independent of strain rate. Therefore, the depth of the imprint determined for this kind of material is the highest.

Comparison of the strain rate and shock wave effect on the estimated hardness was carried out using numerical analysis. Profiles of the imprint estimated using FEM are shown in Fig. 4. It may be seen that, in the case of indentation tests using the steel ball, the depth and diameter of the imprint for steel are significantly lower than those for other materials. The lowest depth of indentation was found for the dynamic
Brinell's test. Decreasing indentation velocity results in higher plastic deformation, since - due to the rate sensitivity effect flow stress at a quasi-static deformation regime is lower than those calculated for dynamic loadings. At ultra-high strain rates induced by ns laser pulse the plastic deformation represented by the imprint depth, is higher than in the case of dynamic loadings. This mechanism was widely discussed in the previous work of the authors [8]. It was found that despite a very short time of the laser pulse (10 ns), plasma generated by the pulse interacts with specimen surface much longer (up to $200 \mathrm{~ns}$ ). Moreover, even after the pressure induced by plasma drops to zero the elasto-plastic mechanical wave is still propagating inside specimen.

The influence of the strain rate on the estimated hardness is shown in Fig. 5(a). It may be observed that dynamic hardness is higher than a quasi-static one for all investigated materials. A further increase in the indentation velocity to ultra-high strain rates induces a lowering of the hardness. Independently of the loading regime, the highest value of the HDL hardness was determined for steel while the lowest for Al. 

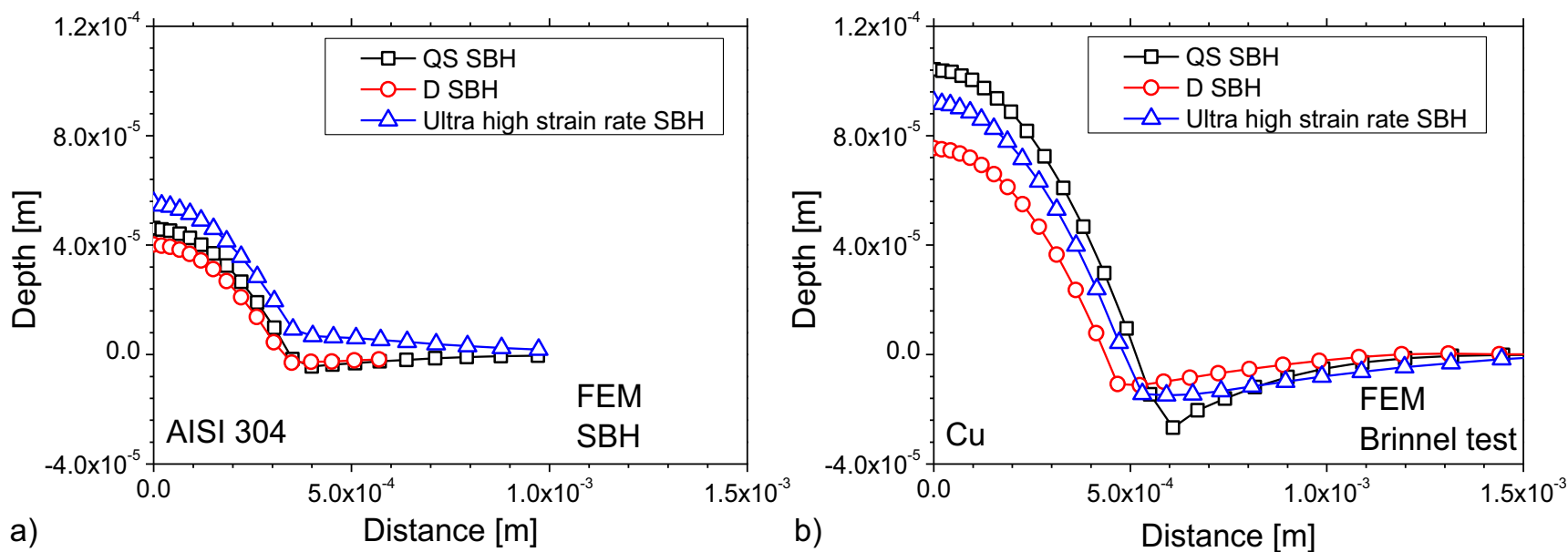

b)

Distance $[\mathrm{m}]$

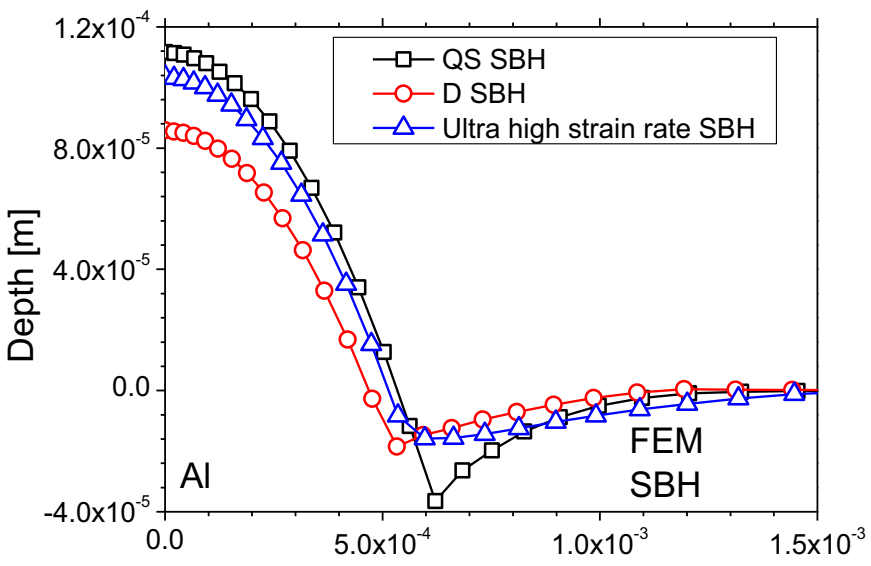

c) Distance $[\mathrm{m}]$

Fig. 4 Numerically calculated profiles of imprints induced by Brinell's tests at various indentation rates for: (a) AISI 304 steel; (b) Cu; (c) Al

A comparison between experimental results and numerical predictions of the HDL hardness is shown in Fig. 5(b). It may be observed that the numerically obtained values are overestimated in comparison to the experimental ones.

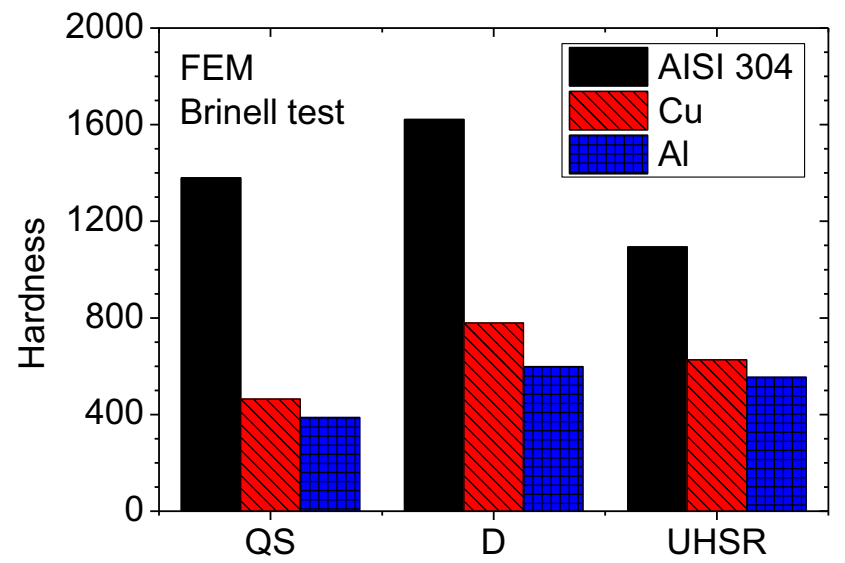

a)

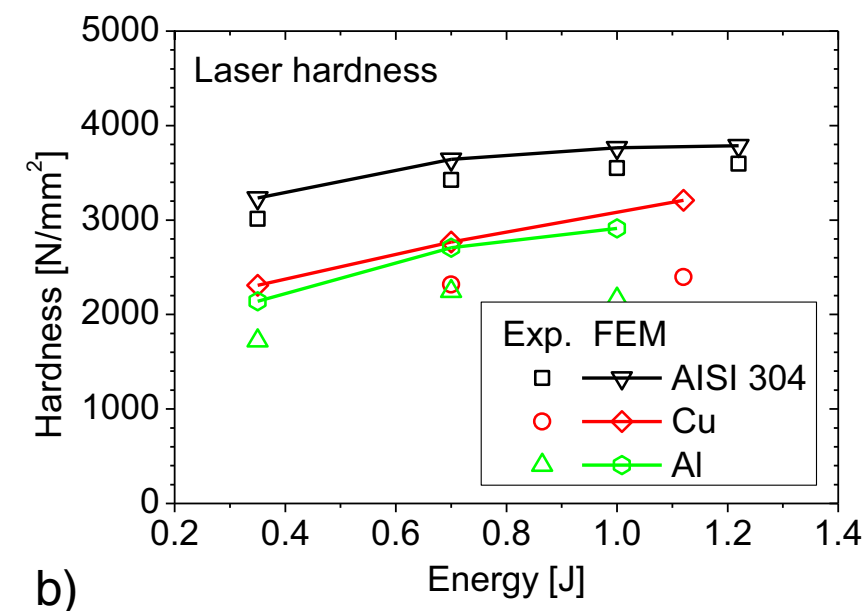

Fig. 5 Numerically predicted influence of (a) indentation rate and (b) pulse energy on the hardness 
Open Access This article is distributed under the terms of the Creative Commons Attribution 4.0 International License (http://creativecommons.org/ licenses/by/4.0/), which permits unrestricted use, distribution, and reproduction in any medium, provided you give appropriate credit to the original author(s) and the source, provide a link to the Creative Commons license, and indicate if changes were made.

Publisher's Note Springer Nature remains neutral with regard to jurisdictional claims in published maps and institutional affiliations.

\section{References}

1. Radziejewska $\mathbf{J}$ (2016) Application of a nanosecond laser pulse to evaluate dynamic hardness under ultra-high strain rate. Opt Laser Technol 78:125-133

2. Rusinek A, Klepaczko JR (2001) Shear testing of a sheet steel at wide range of strain rates and a constitutive relation with strain-rate and temperature dependence of the flow stress. Int J Plast 17:87-115
3. Moćko W, Rodríguez-Martínez JA, Kowalewski ZL, Rusinek A (2012) Compressive viscoplastic response of 6082-T6 and 7075-T6 aluminium alloys under wide range of strain rate at room temperature: Experiments and modeling. Strain 48:498-509

4. Kolsky H (1949) An investigation of the mechanical properties of materials at very high rates of deformation of loading. Proc Phys Soc B62:647-700

5. Fabbro R, Fournier J, Ballard P, Devaux D, Virmont J (1990) Physical study of laser-produced plasma in confined geometry. J Appl Phys 68:775-784

6. Correa C, Peral D, Porro JA, Díaz M, Ruiz de Lara L, García-Beltrán A, Ocaña JL (2015) Random-type scanning patterns in laser shock peening without absorbing coating in 2024-351 Al alloy: A solution to reduce residual stress anisotropy. Opt Laser Technol 73:179-187

7. Peyre P, Chaieb I, Braham C (2007) FEM calculations of residual stresses induced by laser shock processing in stainless steels. Model Simul Mater Sci Eng 15:205-221

8. Moćko W, Radziejewska J, Sarzyński A, Strzelec M, Marczak J (2017) Analysis of the plastic deformation of AISI 304 steel induced by the nanosecond laser pulse. Opt Laser Technol 90:165-173 